\title{
PCB Loading from Sediment in the Hudson River: Congener Signature Analysis of Pathways
}

Jonathan B. Butcher, Edward A. Garvey

Environmental Science and Technology

Number of pages: 6

Number of figures: 3

Number of tables: 1 


\section{Additional Figures}

Three additional figures, referenced in the main text, are included as supporting information.

Thompson Island Pool Sediment Congener Concentration

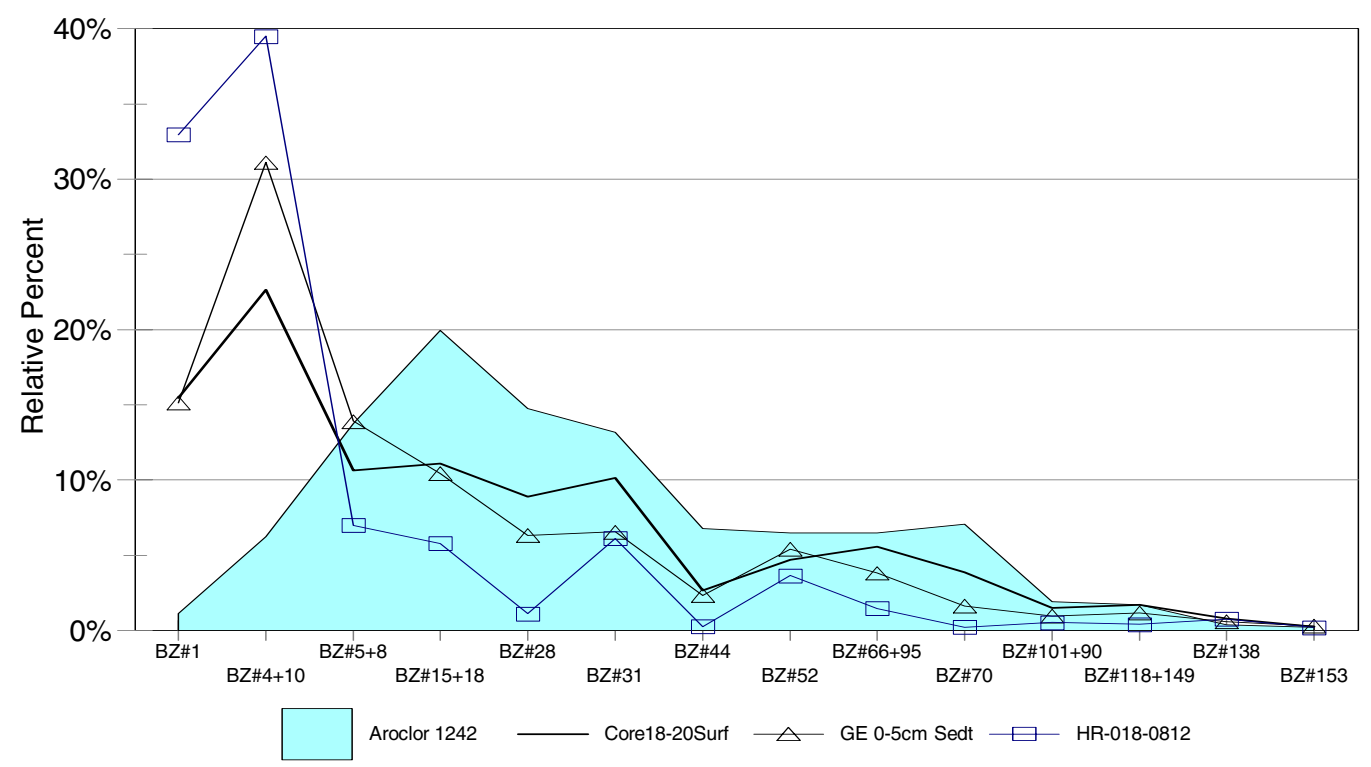

Figure S-1. PCB Congener Pattern in Thompson Island Pool Sediment Compared to Aroclor 1242. 
Summer 1997 Derived Sediment Concentrations

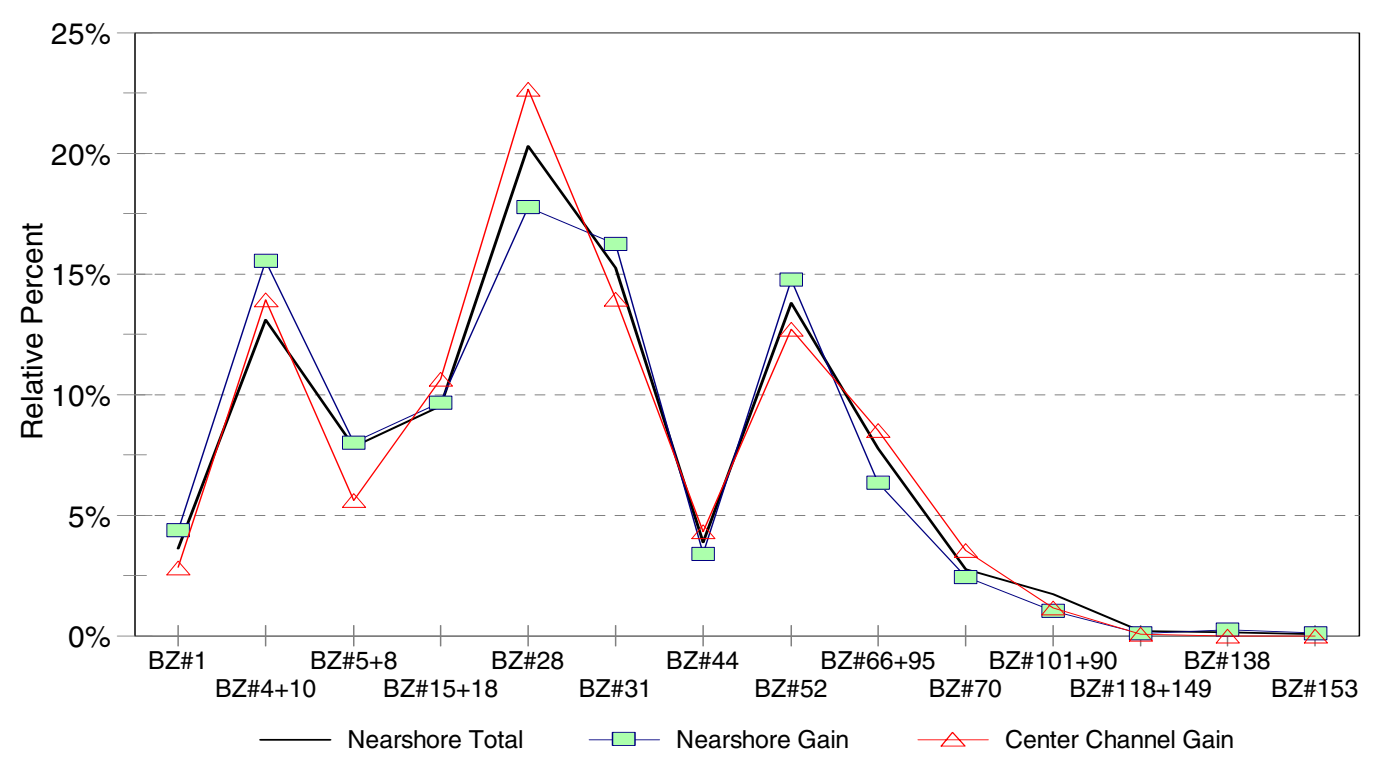

Figure S-2. Estimated Surface Sediment Concentration to Support a Porewater Source of

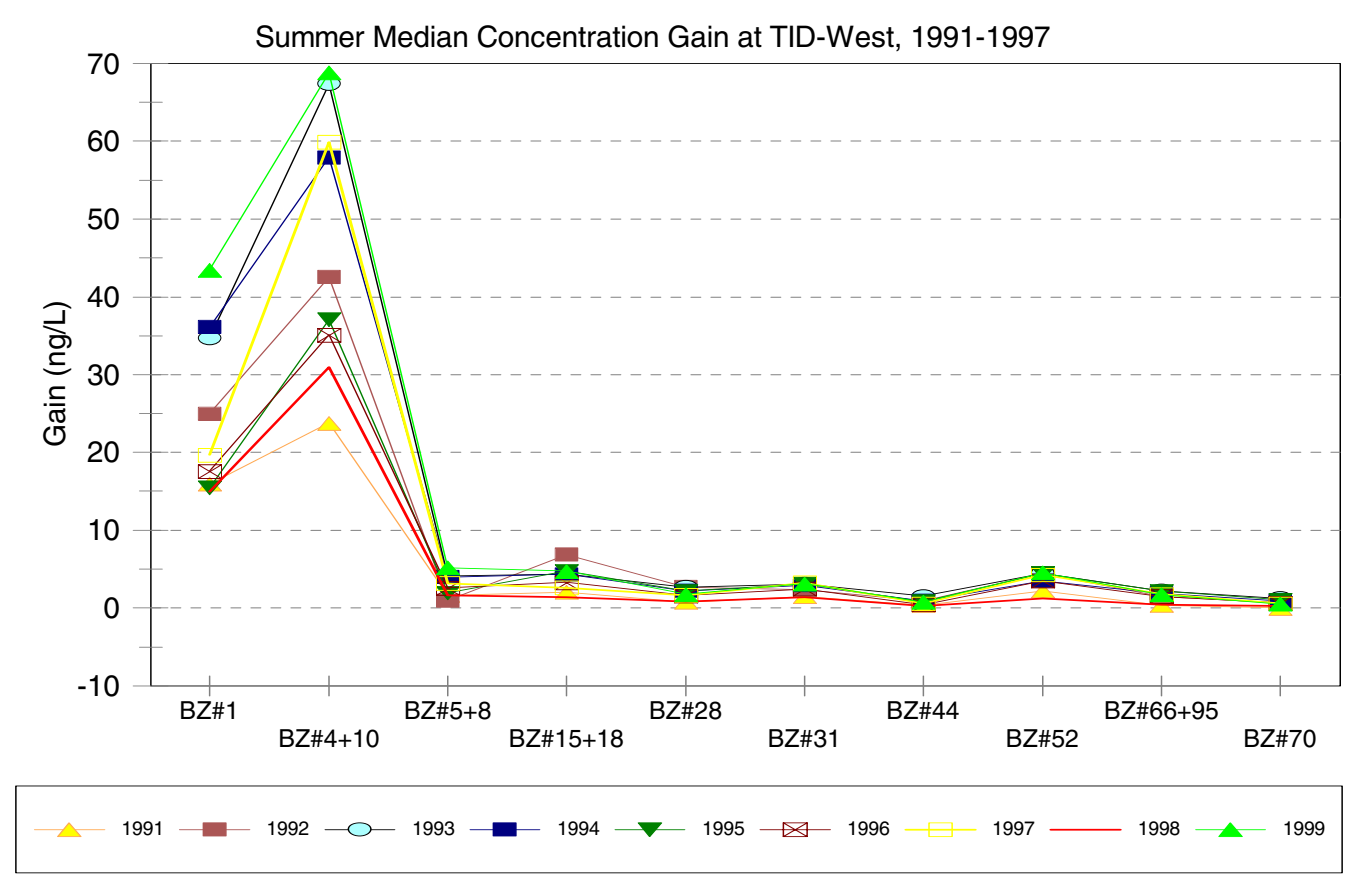

\section{Observed PCB}


Figure S-3. Summer Concentration Gain of PCB Congeners across the Thompson Island Pool for 1991-1999.

\section{Role of Volatilization in Observed Congener Pattern}

Differential volatilization may have a confounding effect on the distribution of congeners in the water column. However, the impact of this phenomenon is limited by short residence times (on the order of 0.6day in the Thompson Island Pool).

As part of the Hudson River RRI/FS modeling effort, model sensitivity to Henry's Law constant was assessed (12). The sensitivity analyses evaluated effects of Henry's Law constants ranging from $0.68 \times 10^{-4}$ to $1.93 \times 10^{-4}\left(\mathrm{~atm}-\mathrm{m}^{3} / \mathrm{mole}\right)$ and found that water column "concentrations are insensitive to the choice of this parameter" for transport throughout the entire 40 miles of the Upper Hudson River from Hudson Falls to the Federal Dam at Albany.

To further assess the importance of this issue, volatilization was assessed using twofilm theory. For low atmospheric PCB concentrations, the air-water transfer rate, $S_{v}$ $\left(\mathrm{g} / \mathrm{m}^{2} / \mathrm{d}\right)$, may be approximated as

$$
S_{v}=\frac{K_{v}}{D}\left[f_{d} C\right]
$$

where $K_{v}$ is the air-water transfer rate $(m / d)$, D is depth $(m), f_{d}$ is the dissolved fraction, and $\mathrm{C}$ is the water column concentration.

The parameter $\mathrm{K}_{\mathrm{v}}$ is given by

$$
K_{v}=\frac{k_{g} k_{l}}{k_{g}+k_{l} / H}
$$


where $\mathrm{k}_{\mathrm{g}}$ is the vapor side mass transfer coefficient, $\mathrm{k}_{\mathrm{l}}$ is the liquid side mass transfer coefficient, and $\mathrm{H}$ is the dimensionless Henry's law constant, equivalent to the Henry's law constant in atm- $\mathrm{m}^{3} / \mathrm{mol}$ normalized to the Universal Gas Constant times temperature in Kelvin.

As shown by Connolly et al. (11), $100 \mathrm{~m} / \mathrm{d}$ is a good approximation for $\mathrm{k}_{\mathrm{g}}$ in the Hudson. The liquid side coefficient, $\mathrm{k}_{1}(\mathrm{~m} / \mathrm{d})$, is a function of molecular weight. Using the approximation adopted for the WASP model,

$$
k_{l}=(M W \cdot v / D)^{0.5} \cdot 86400,
$$

where MW is the molecular weight $(\mathrm{g} / \mathrm{mole})$ and $v$ is the velocity $(\mathrm{m} / \mathrm{s})$. For the Thompson Island Pool of the Hudson River, the average velocity is about $0.25 \mathrm{~m} / \mathrm{s}$, and the average depth is about $3 \mathrm{~m}$.

For transit across a fixed distance, the relative change in concentration is given by

$$
S_{v} / C=\left(K_{v} / D\right) \cdot f_{d} \cdot t,
$$

where $t$ is the transit time (d). The Thompson Island Pool is approximately 8 miles in length, and the relevant length scale is from the centroid of the reach to the downstream station, or 4 miles. This converts to a travel time of 0.3 days at average flows.

Henry's constants were taken from Brunner et al. (S-1), while $f_{d}$ was taken as the truly dissolved fraction reported by Butcher et al. (8). Using these values yields the estimates shown in the following table for transit to the observation point at Thompson Island Dam for the two dominant light congeners and a representative heavy PCB congener: 
Table S-1. Analysis of Volatilization Effects on Congener Ratios

\begin{tabular}{|l|l|l|l|}
\hline & BZ\#1 & BZ\#4+10 & BZ\#101+90 \\
\hline $\begin{array}{l}\text { Henry's constant } \\
\left(\mathrm{atm}-\mathrm{m}^{3} / \mathrm{mole}\right)\end{array}$ & $6.92 \mathrm{E}-04$ & $2.30 \mathrm{E}-04$ & $9 \mathrm{E}-05$ \\
\hline $\mathrm{MW}(\mathrm{g} / \mathrm{mole})$ & 187 & 223 & 326 \\
\hline$k_{l}(\mathrm{~m} / \mathrm{d})$ & 0.647 & 0.610 & 0.538 \\
\hline$K_{v}(\mathrm{~m} / \mathrm{d})$ & 0.527 & 0.370 & 0.218 \\
\hline$f_{d}$ & 0.44 & 0.40 & 0.31 \\
\hline$S_{\nu} / C\left(\mathrm{~d}^{-1}\right)$ & 0.0772 & 0.0493 & 0.0226 \\
\hline
\end{tabular}

As expected, the greatest rate of volatilization loss is for BZ\#1. Using these estimates, volatilization is expected to result in a change in the ratio of BZ\#1 to BZ\#4 of less than 1 percent during transit across the Thompson Island Pool at average flow conditions. The change in the ratio of BZ\#1 to BZ\#101 is about 1.6 percent. Even at a velocity of $0.1 / \mathrm{ms}$, the change in ratios is less than 3 percent.

The potential alteration of congener ratios within the Thompson Island Pool as a result of volatilization thus appears to be small, and much less than the observed difference between porewater and surface water.

\section{Supporting Information Additional Reference}

(S-1) Brunner, S.; Hornung, E.; Santi, H.; Wolff, E.; Pittinger, O.G. Environ. Sci. Technol. 1990, 24(11), 1751-1754. 